\title{
UJI VALIDITAS SABAROUD GLUKOSA AGAR HIPERTONIK UNTUK MENDETEKSI Candida sp
}

\author{
Tuty Widyanti ${ }^{1)}$, Mujahidah Basarang ${ }^{1)}$, Nurul Afiah ${ }^{1)}$ \\ 1) Akademi Analis Kesehatan Muhammadiyah Makassar \\ Alamat Korespondensi: vandinu@yahoo.com
}

\begin{abstract}
Abstrak
Jamur merupakan agen yang juga memberi pengaruh pada penyakit paru disebabkan oleh Mycobacterium tuberculosis. Gejala umum infeksi jamur paru sama dengan infeksi tuberkulosis ataupun dengan mikroba lainnya. Infeksi jamur paru sering tidak terdiagnosa karena tidak ada gejala yang khas. Infeksi jamur paru sering menyertai penyakit lain sehingga pengobatan terhadap infeksi jamur paru sering terlambat diberikan. Identifikasi kultur konvensional dan dilanjutkan dengan tes biokimia membutuhkan waktu yang lama oleh karena itu diperlukan metode fenotip yang mudah, sederhana dan murah untuk mengidentifikasi antara Candida sp. Tujuan penelitian ini adalah mendeteksi keberadaan jamur dengan metode kultur dari sampel bilasan bronkus dan bilasan lambung. Penelitian ini merupakan penelitian eksperimental untuk mengetahui pertumbuhan jamur Candida sp yang diidolasi dari bilasan lambung dan bronkus suspek tuberculosis yang negatif BTA pada medium Sabaroud Agar Hipertonik. Hasil penelitian ditemukan $100 \%$ sampel menunjukkan pertumbuhan Candida sp dari sampel bilasan bronkus dan bilasan lambung tumbuh pada medium SDA Hipertonik $37^{\circ} \mathrm{C}$ dengan rata-rata pertumbuhan 24 jam. Koloni Candida sp yang tumbuh pada medium SDA Hipertonik $37^{\circ} \mathrm{C}$ akan tampak berwarna putih, halus, licin, ukuran koloni dari kecil sampai ukuran besar, jika koloni sudah berumur tua akan berwarna kecoklatan. Candida sp secara mikroskopik berbentuk bulat sampai lonjong dan memiliki pertunasan yang dinamakan budding.
\end{abstract}

Kata Kunci: Candida sp., Sabaroud Glukosa Agar Hipertonik

\section{PENDAHULUAN}

Penyakit infeksi masih tetap menjadi masalah utama kesehatan di Indonesia salah satunya adalah penyakit tuberkulosis paruyang disebabkan oleh Mycobacterium tuberculosis (Sudoyo, 2007). Laporan WHO yang terbaru (2006), masih menempatkan Indonesia sebagai negara dengan pasien $\mathrm{TB}$ terbanyak ke-3 di dunia setelah India dan Cina. Diperkirakan jumlah pasien tuberkulosis di Indonesia sekitar 10\% dari total jumlah pasien tuberkulosis di dunia (Pedoman Nasional Penanggulangan Tuberkulosis, 2006).

Jamur merupakan agen yang juga memberi pengaruh pada penyakit paru disebabkan oleh Mycobacterium tuberculosis. Menurut Samie A.,dkk., (2012), jika kurang lebih sekitar dua dekade terakhir invasi infeksi jamur mengalami peningkatan. Saat ini angka kematian yang disebabkan oleh infeksi oportunistik mengalami peningkatan yang cukup signifikan yang disebabkan oleh agen immunokompeten yaitu jamur. (Jawetz et al., 2007). Invasi infeksi jamur dilaporkan mengalami peningkatan menjadi $26 \%$ pada pasien kronik dan immunosupresif menjadi $26 \%$ (Topley dan Wilson, 2005).

Tingkat infeksi jamur tergantung pada ukuran inokulum organisme jamur dan tingkat resistensinya terhadap inangnya. Infeksi jamur dapat menyebabkan fungaemia sehingga dapat menyebabkan immunosupresif pada individu yang terinfeksi. Beberapa jenis jamur yang dapat menyebab fungaemia yaitu Candida albicans, Penicillium marneffei, Histoplasma capsulatum, Aspergillus spp., Rhizomucor, Absidia spp., Cunninghamella spp., ( Pfaller and Diekema, 2006).

Gejala umum infeksi jamur paru sama dengan infeksi tuberkulosis ataupun dengan mikroba lainnya. Gejala itu berupa batuk-batuk, batuk darah, banyak dahak, sesak, demam, nyeri dada dan bisa juga tanpa gejala. Infeksi jamur paru sering 
tidak terdiagnosa karena tidak ada gejala yang khas. Infeksi jamur paru sering menyertai penyakit lain sehingga pengobatan terhadap infeksi jamur paru sering terlambat diberikan (Sudoyo, 2007). Kandidiasis merupakan infeksi jamur tersering pada manusia, dapat terjadi di seluruh dunia dan menyerang segala usia, baik laki-laki maupun wanita (Todar, 2005). Oleh karena itu diperlukan diagnosis sesuai dengan standar mikrobiologi dan pengobatan yang krusial.

Permasalahan lain yang kemudian timbul ialah bahwa baik gambaran klinik maupun radiologik penderita infeksi jamur paru tidak khas (Sudoyo, 2007). Beberapa identifikasi kultur konvensional dan dilanjutkan dengan tes biokimia membutuhkan waktu yang lama (Mandigan M.T., dkk, 2009). Oleh karena itu diperlukan metode fenotip yang mudah, sederhana dan murah untuk mengidentifikasi antara Candida $s p$. Berdasarkan pemikiran ini, maka perlu dikembangkan suatu metode identifikasi jamur secara fenotip menggunakan media modifikasi dengan biaya relatif murah, cepat dan mudah diaplikasikan yaitu sabaroud glukosa hipertonik. Penelitian Gomes, dkk. (2011) menemukan bahwa Candida albicans dapat tumbuh pada sabouraud dekstrosa agar hipertonik sementara Candida dubliniensis tidak tumbuh.

\section{METODE PENELITIAN}

\section{Alat dan Bahan}

Alat-alat yang digunakan dalam penelitian ini adalah autoklaf (Sanyo), Bio Safety Cabinet (ESCO class II Type A2), lampu bunsen, inkubator (Memmert), kaca objek (Sail Brand), kotak kaca objek, lemari asam (ESCO), mikroskop (Nikon), neraca analitik (Kernew), ose bulat, pH meter (Schoft Instrument), plate well, rak tabung, sentrifugasi (Sorvall Legendt), Falcott), stopwatch (lingcheng), tabung eppendorf (Axygen), tabung Falcon 50ml, vortex (Heidolph), pinset, gunting, waterbath (Memmert), freezer, gelas kimia, erlenmeyer, sendok timbangan, dan stirer magnetik.
Bahan-bahan yang digunakan dalam penelitian adalah sampel bilasan bronkus, bilasan lambung, kapas, alkohol, karbol fuksin, methilen blue, glukosa, agar, $\mathrm{NaCl}$ dan air steril.

\section{Prosedur Kerja \\ Preparasi sampel}

Pengumpulan sampel penelitian dilakukan di Infection Centre Rumah Sakit Wahidin Sudirohusodo. Sampel yang dikumpul berupa bilasan bronkus dan bilasan lambung suspek tuberkulosis. Suspek tuberkuolosis, tidak sedang menjalani terapi pengobatan anti jamur dan bersedia untuk mengikuti penelitian dengan menandatangani informed consent yang telah dikeluarkan oleh Komisi Etik Fakultas Kedokteran Universitas Hasanuddin. Sampel-sampel ini kemudian dibawa ke Laboratorium Tuberkulosis Hum-RC (Hasanuddin University Medical Research Centre) Fakultas Kedokteran Universitas Hasanuddin Makassar untuk dilakukan pemeriksaan.

Sampel sputum suspek tuberculosis diwarnai dengan metode Zhiel-Nielsen kemudian diamati di bawah mikroskop. Bilasan lambung dan bronkus BTA negatif merupakan sampel penelitian yang selanjutnya di kultur untuk mengidentifikasi jamur Candida $s p$.

Pembuatan Sabouraud glukosa agar hipertonik

Bahan medium Sabouraud dimasukkan ke dalam labu kimia steril kemudian dicampur. Medium kemudian diautoclave pada suhu $121^{\circ} \mathrm{C}$ selama 15 menit . Medium yang telah jadi dituangkan ke dalam botol McCartney steril sebanyak 6-8 $\mathrm{ml}$.

\section{Kultur Sabouraud Glukosa Agar} Hipertonik

Sampel diambil dengan menggunakan ose bulat kemudian diinokulasi pada medium Sabouraud Glukosa Agar Hipertonik 7x24 jam pada suhu $28^{\circ} \mathrm{C}$.

\section{Smear dengan pengecatan Gram}

Biakan Candida sp diambil menggunakan ose bulat diteteskan pada permukaan gelas benda dan dibuat preparat dengan ukutan $2 \times 3 \mathrm{~cm}$, kemudian difiksasi pada hotplate selama 2 
menit. Selanjutnya dituangkan cristal violet dibiarkan 2 menit, cuci dengan air mengalir, lalu dituangkan lugol dibiarkan 38 detik, cuci dengan air mengalir. Lalu tuangkan alkohol 96\% dibiarkan 10 detik, cuci dengan air mengalir. Kemudian tuangkan Fuchsin alkalis dibiarkan 40 detik, cuci dengan air mengalir.

\section{Interpretasi}

Koloni jamur pada media Sabouraud Glukosa Agar Hipertonik berwarna putih, agak mengkilat dan halus. Sel khamir yang diamati berbentuk bulat atau oval.

\section{HASIL PENELITIAN}

Penelitian ini menggunakan sampel bilasan bronkus dan bilasan lambung dari 30 orang suspek tuberkulosis. Pengambilan sampel dan pengumpulan data (umur, jenis kelamin, riwayat tentang penyakit tuberkulosis, riwayat penyakit lainnya, riwayat pengobatan) dilakukan dengan wawancara menggunakan daftar pertanyaan oleh petugas laboratorium yang terlatih di Infection Centre Rumah Sakit Wahidin Sudirohusodo. Jumlah sampel ditentukan berdasarkan rumus Simple Random Sampling. Total sampel dalam penelitian ini yaitu 30 bilasan bronkus dan bilasan lambung dari penderita suspek Tuberkulosis di Infection Centre Rumah Sakit Wahidin Sudirohusodo yang terbagi atas $18(60 \%)$ sampel bilasan bronkus dan $12(40 \%)$ sampel bilasan lambung dari penderita suspek tuberkulosis.

Sebelum melakukan proses kultur pada medium Sabaroud Dektrosa Agar Hipertonik $37^{\circ} \mathrm{C}$ terlebih dahulu dilakukan pemeriksaan langsung secara mikroskopik terhadap sampel bilasan bronkus dan lambung menggunakan metode smear dengan pewarnaan Ziehl-Neelsen. Selanjutnya semua sampel bilasan bronkus diinokulasikan pada medium Sabaroud Dektrosa Agar Hipertonik $37^{\circ} \mathrm{C}$ kemudian diinkubasi selama 3 hari untuk melihat pertumbuhan Candida albicans pada media tersebut. Berikut ini hasil smear dan kultur sampel bilasan broncus dan lambung yang ditunjukkan pada tabel 1.
Tabel 1.Perbandingan Tingkat Isolasi

Jamur Candida sp Bilasan

Bronkus dan Lambung

Suspek Penderita TB pada SDA Hipertonik

\begin{tabular}{cccc}
\hline \multirow{2}{*}{ Media } & \multicolumn{3}{c}{ Hasil Kultur } \\
\cline { 2 - 4 } & Positif & Negatif & Kontaminasi \\
\hline SDA & 30 & - & 5 \\
Hipertonik & $(100 \%)$ & - & $(16.7 \%)$ \\
\hline
\end{tabular}

Berdasarkan hasil kultur sampel sputum BTA pada medium Sabaroud Dektrosa Agar Hipertonik $37^{\circ} \mathrm{C}$, jumlah sampel yang positif pertumbuhan Candida albicans yaitu $30(100 \%)$, sedangkan yang negatip pertumbuhan Candida albicans tidak ada dan kontaminasi yaitu 5 (16.7\%).

Tabel2.Rata-Rata Waktu Pertumbuhan

Koloni Jamur Candida sp

Bilasan Bronkus dan

Lambung Suspek Penderita

TB pada Media Sabaroud

Dekstrosa Agara Hipertonik

\begin{tabular}{cccc}
\hline \multirow{2}{*}{ Media } & \multicolumn{3}{c}{ Pertumbuhan Jam } \\
& \multicolumn{2}{c}{ ke- } & \multirow{2}{*}{$\mathbf{4 8}$} \\
\cline { 2 - 3 } & $\mathbf{2 4}$ & $\mathbf{4 8}$ \\
\hline SDA & 27 & 3 & $\mathbf{3 0}$ \\
Hipertonik & $(90 \%)$ & $(10 \%)$ & $(\mathbf{1 0 0 \%})$ \\
\hline
\end{tabular}

Untuk rata-rata hari pertumbuhan koloni untuk Candida albicans pada medium Sabaroud Dektrosa Agar Hipertonik $37^{\circ} \mathrm{C}$ yaitu 1 hari yang berkisar antara 1-2 hari.

Hasil dari kultur tersebut yang positip selanjutnya dikonfirmasi dengan pemeriksaan mikroskopik dengan menggunakan pewarnaan gram yang bertujuan untuk menegaskan kembali apakah koloni yang tumbuh tersebut benar adalah Candida albicans.

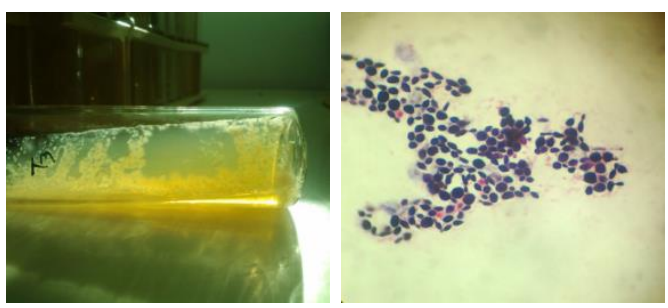

Gambar 1. (a) Koloni Candida sp pada Media SDA Hipertonik (b)

Mikroskopik Candida $s p$ dari Sampel Bilasan Bronkus dan Lambung

Penelitian ini menggunakan sampel bilasan bronkus dan bilasan lambung dari 
30 orang suspek tuberkulosis. Pengambilan sampel dan pengumpulan data (umur, jenis kelamin, riwayat tentang penyakit tuberkulosis, riwayat penyakit lainnya, riwayat pengobatan) dilakukan dengan wawancara menggunakan daftar pertanyaan oleh petugas laboratorium yang terlatih di Infection Centre Rumah Sakit Wahidin Sudirohusodo. Jumlah sampel ditentukan berdasarkan rumus Simple Random Sampling. Sampel pada penelitian ini yaitu 30 terdiri atas 18 sampel bilasan bronkus dan 12 sampel bilasan lambung dari penderita suspek tuberkulosis.

Sampel kemudian diperiksa secara mikroskopok sebagai diagnosis awal infeksi Mycobacterium karena metode pemeriksaan smear dapat menunjukkan hasil pemerikaaan yang cepat. Selain itu pemeriksaan secara mikroskopik dengan basil tahan asam (BTA) merupakan pemeriksaan yang sederhana, murah dan cukup sensitif untuk mendukung diagnosis penyakit tuberkulosis serta untuk menilai kemajuan pengobatan.

Berdasarkan data penelitian (tabel 1) menunjukkan bahwa ditemukan BTA negatip pada 18 sampel bilasan bronkus dan 12 sampel bilasan lambung dari penderita suspek tuberkulosis.

Setelah dilakukan pemeriksaan mikrokospik selanjutnya sampel diinokulasikan pada medium pertumbuhan yaitu SDA Hipertonik $37^{\circ} \mathrm{C}$ bertujuan untuk untuk mengetahui tingkat kemampuan baik sensitifitas maupun sensifitas medium SDA Hipertonik $37^{\circ} \mathrm{C}$ dalam mengisolasi jamur Candida albicans. Penelitian Gomes, dkk. (2011) menemukan bahwa Candida albicans dapat tumbuh pada sabaroud dekstrosa agar hipertonik sementara Candida dubliniensis tidak. Koloni Candida albicans yang tumbuh pada medium SDA Hipertonik $37^{\circ} \mathrm{C}$ tampak berwarna putih, halus, licin, ukuran koloni dari kecil sampai ukuran besar, jika koloni sudah berumur tua akan berwarna kecoklatan (Gambar 1).

Dari data penelitian diperoleh bahwa medium SDA Hipertonik $37^{\circ} \mathrm{C}$ memilki tingkat pertumbuhan koloni yaitu
$30(100 \%)$ jumlah sampel yang positif pertumbuhan Candida albicans. Dari 30 sampel ini terdapat $5(16.7 \%)$ sampel yang ditumbuhi jamur jenis lain yaitu Aspergillus sp. Kultur menjadi sangat penting untuk menghindari kesalahan dalam rutin identifikasi. Dari hasil penelitian diperoleh pula rata-rata hari pertumbuhan Candida spp antara medium SDA Hipertonik $37^{\circ} \mathrm{C}$ yaitu 1 hari (24 jam) setelah inokulasi (Tabel 2). Namun terdapat $3(10 \%)$ sampel dengan lama pertumbuhan 48 jam setelah inokulasi. Hal ini sesuai dengan penelitian Gomes, dkk. (2011), yang menyatakan bahwa pertumbuhan Candida albicans pada SDA Hipertonik berkisar antara 24-48 jam.

Setelah didapatkan hasil kultur yang positif dari medium SDA Hipertonik $37^{\circ} \mathrm{C}$ selanjutnya dilakukan uji konfirmasi dengan pemeriksaan mikroskopik kembali menggunakan pewarnaan sederhana. Uji konfirmasi ini dilakukan bertujuan untuk menegaskan kembali apakah koloni yang tumbuh pada media tersebut benar adalah Candida albicans (Gambar 3). Hasil pengamatan mikrokopik tersebut menunjukkan keberadaan Candida albicans pada media. Candida albicans nampak adanya budding atau pertunasan pada ujung blastopora.

\section{KESIMPULAN}

Dari hasil penelitian yang dilakukan maka dapat disimpulkan bahwa:

1. Candida sp. dari bilasan bronkus dan bilasan lambung tumbuh pada medium SDA Hipertonik $37^{\circ} \mathrm{C}$ dengan rata-rata pertumbuhan 24 jam.

2. Koloni Candida spp yang tumbuh pada medium SDA Hipertonik $37^{\circ} \mathrm{C}$ akan tampak berwarna putih, halus, licin, ukuran koloni dari kecil sampai ukuran besar, jika koloni sudah berumur tua akan berwarna kecoklatan.

\section{SARAN}

Sebagai pertimbangan untuk peneliti selanjutnya, dapat dilakukan peneltian mengenai:

1. Penggunaan PCR untuk mendeteksi keberadaan Candida sp dari sampel bilasan broncus dan bilasan lambung. 
2. Kultur sampel bilasan broncus dan bilasan lambung pada medium SDA Hipertonik dengan membandingkan suhu ikubasi.

\section{DAFTAR PUSTAKA}

Gomes, dkk. 2011. Differentiation between Candida albicans and Candida dubliniensis using hypertonic Sabouraud broth and tobacco agar. Revista da Sociedade Brasileira de Medicina Tropical 44(4):457-460, jul-ago, 2011.

Jawetz, dkk. 2007. Mikrobiologi Medik Edisi ke 24. McGraw Hill.

Mandigan, M.T., dkk. 2009. Biology of Microorganism. San Francisco: Pearson International Edition.

Perkumpulan Pemberantasan Tuberkulosis INDONESIA. 2006. Jakarta: Jurnal Tuberkulosis Indonesia Vol III No 2.

Pfaller, MA., dkk. 2006. Infeksi Opportunistik Jamur Patogen , Candida albicans dan Aspergillus fumigatus. J. Clin. Microbiol, 42: 4419-4431.

Samie, A.,dkk. 2012. Diversity of respiratory yeast from HIV infected patients with tuberculosis, their drug resistance and biofilm formation, University of Venda, Departement Of Microbiology , South Africa, African Journal Of Microbiology Research Vol. 6 (2), pp 257-266, 16 January 2012.

Sudoyo, A.W., dkk. 2007. Buku Ajar Ilmu Penyakit Dalam Jil II Ed 4. Jakarta: Pusat Penerbitan Departemen Ilmu Penyakit Dalam FKUI.

Todar. 2005. Tuberculosis, Todar's Online Textbook of Bacteriology. Available from: www.textbookofbacteriology.net.

Topley, Wilson. 2005. Mikrobiologi dan Infeksi Mikroba, Mikologi Medik, Edisi ke 10. Dipublikasi oleh Hodder Arnold. 